\title{
Etiologic Factors of Infertility in a Referral Hospital (BSMMU, Bangladesh)
}

\author{
BEGUM ROKEYA ANWAR, ${ }^{1}$ PARVEEN FATIMA,${ }^{2}$ NASIM AFZA,${ }^{3}$ TAZKIA TARANNUM,${ }^{4}$ NAZNEEN BEGUM, ${ }^{5}$ SYEDA \\ UMME KULSUM, ${ }^{6}$ SHAILA PARVEEN ${ }^{7}$
}

\begin{abstract}
:
Background: Infertility is defined as the failure in pregnancy after one year of unprotected intercourse. Several centers have reported different causes of infertility. The most common causes of infertility include: Female factors such as ovulation dysfunction and tubal factor; male factors like sperm disturbance as well as; both male and female factors and unexplained infertility. The aim of this study was to find out the etiologic factors of infertility in BSMMU (Bangabandhu Sheik Mujib Medical University, Dhaka, Bangladesh)

Methods: This cross sectional study was done at the Out Patient Department (OPD) of infertility in BSMMU during the period of December 2004 to March 2005. One hundred infertile couples with necessary investigations were reviewed for the study.

Results: In this study the frequency of primary and secondary infertility was $56 \%$ and $44 \%$ respectively. Among 100 couples $57 \%$ had female factor, $25 \%$ had both male and female factors and in $3 \%$ had male factor and in 15\% of couple, the causes of infertility were unknown. Among women, different infertility factors included: Tubal factor 33\%, Ovarian factor $12 \%$ and endometriosis $11 \%$. In this study tubal blockage were detected in $50 \%$ cases of female secondary subfertility following Menstruation Regulation (M/R). Result showed $82 \%$ of men had normal spermogram $28 \%$, had sperm disturbance including Oligospermia, Asthenospermia, Oligoasthenospermia and teratospermia.
\end{abstract}

Conclusion: Although female factor was the most common cause of infertility in BSMMU, we can not conclude that this factor is the most common causes of infertility in Bangladesh. Since this centre is considered as referral centre especially for female infertility. We suggest performance of similar researches with big sample size in different institution to evaluate most common causes of infertility in Bangladesh.

Key words: Infertility, Etiology, Male, Female, Combined, Unexplained factors.

\section{Introduction:}

Infertility is defined as the inability of a couple to achieve conception after one year of unprotected coitus. It affects one in seven couples. ${ }^{1}$ The levels and patterns of infertility apparently vary widely and also are different in developed countries compared to those in developing region of the world $^{(2)}$. Cultural, socioeconomic, health care practices and policies and environmental factors play a major role in the prevalence and etiology of infertility. ${ }^{3}$ Also the proportions of causes of infertility have changed over time ${ }^{(4)}$. The most

1. Junior Consultant (Gynae), Savar Health Complex, Savar, Dhaka

2. Professor, Head of the Department, Department of Infertility, BSMMU, Dhaka

3. Assistant Professor, Gynae \& Obs, DMCH, Dhaka

4. Student, MBBS $5^{\text {th }}$ year, Bangladesh Medical College, Dhaka

5. Assistant Professor, Gynae \& Obs, BSMMU, Dhaka

6. Assistant Professor, Gynae \& Obs. Sikder Women's Medical College, Dhaka

7. Assistant Professor, Gynae \& Obs., NICR\&H, Dhaka

Correspondence: Begum Rokeya Anwar, Junior Consultant (Gynae), Savar Health Complex, Savar, Dhaka cost-effective approach to solving the infertility problem is prevention and education. Further research in both developed and developing countries is needed to understand the high prevalence and causes of infertility ${ }^{(5)}$ There are only a few reports on this topic in Bangladesh. 6,7 Therefore, determination of the clinical patterns and a review of the major causes of infertility in BSMMU, Bangladesh were the main objectives of this study.

Materials :

Study design: Cross sectional.

Place of Study: Out Patient Department (OPD) of Infertility at Bangabandu Sheik Mjuib Medical University (BSMMU).

Study Period: December 2004 to March 2005.

Inclusion Criteria: Couples with more than one years of sub-fertility. 100 couples were reviewed where necessary investigation of couples were done to detect etiological factors.

Exclusion criteria: Infertile woman above 45 years of age, couples without necessary investigations were excluded from the study. 


\section{Methods:}

Permission: Necessary permission was obtained from the component authority of Bangabandu Sheik Mujib Medical University (BSMMU). The said were communicated verbally to the study population and then the consent from the infertile couples were taken for subsequent investigations.

Ethical consideration: All the patients were given a comprehensive explanation.

Development of Questionnaire: A questionnaire was designed encompassing all clinical information. It also included investigations done to detect causes of infertility. Data were collected from the review of 100 infertile couples attending the out patient department (OPD) of infertility of Bangabandu Sheik Mujib Medical University (BSMMU). Detailed history was taken; complete Physical examination and investigation in the female partners were done to confirm etiology responsible for female factor infertility. The specific investigations performed for the female partners included tests for documentation of ovulation (gonadotrophins and steroids assays and ultrasonography), test for tubal patency and loparoscopy (when indicated). Tubal patency was assessed hysterosalpinography, Laparoscopy was performed in some cases to study tubal diseases and to look for endometriosis. For male reports of semen analysis were studied to detect male factor infertility.

Statistical analysis: Collected data were analyzed using statistical package for the social science (SPSS) program software.

\section{Result:}

The total of 100 infertile couples were assessed in this study. Of this, $45(56 \%)$ couples had primary infertility and $37(44 \%)$ had secondary infertility. The mean age $( \pm$ SD) of the women was $27.73 \pm 3.46$ (range 18- 40 years) the mean duration $( \pm \mathrm{SD}$ ) of infertility at the time of presentation to infertility unit was $4.3 \pm .46$ years. The BMI of female partner was $23.16 \pm 1.08$ (rage $20-29 \mathrm{~kg} / \mathrm{m}^{2}$ ) The number of middle classes were attending in hospital was about 59\% with monthly income of mean $5813 \pm 895.4$ taka per months.

In this study only female and male factors were responsible in $57 \%$ and $3 \%$ cases respectively (Table- 1 pie chart). In $25 \%$ cases both male and female were responsible as combined factor infertility, remaining $15 \%$ were unexplained infertility and Female factors were responsible for sub fertility in $82 \%$ cases. Among them $56 \%$ were primary sub fertility and $44 \%$ were secondary sub fertility (Table 2 ). The ratio of primary and secondary infertility were 1.2.1. Regarding secondary infertility 18 cases (48.65) were related to MR out of 37 cases.

Number of patient $\mathrm{n}=100$

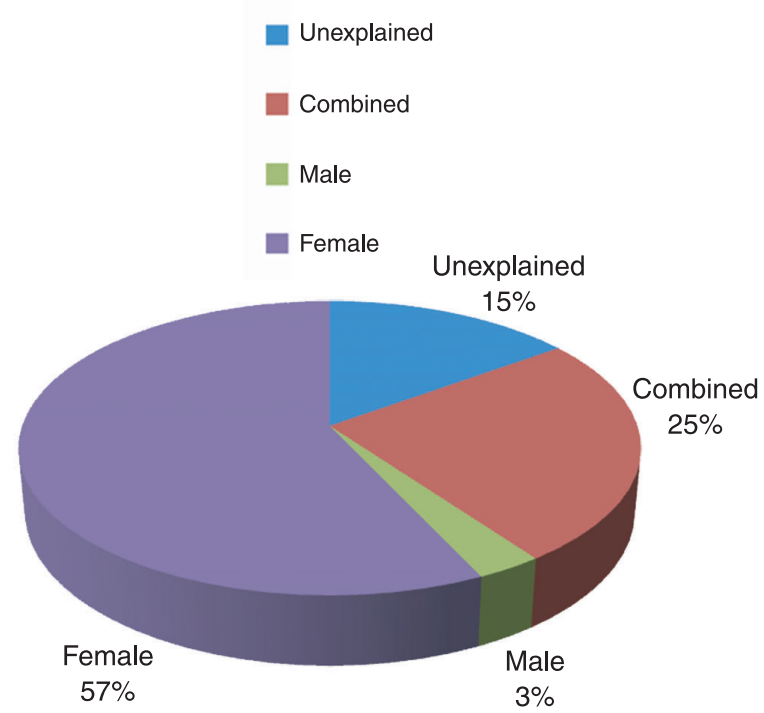

Fig.-1: Factors responsible for infertility

Table-I

\begin{tabular}{lcc}
\hline Type of Infertility & Number of Patients & Percentage \\
\hline Male & 3 & $3 \%$ \\
Female & 57 & $57 \%$ \\
Combined & 25 & $25 \%$ \\
Unexplained & 15 & $15 \%$ \\
\hline
\end{tabular}

Table-II

Incidence of infertility $(n=100)$

\begin{tabular}{lcc}
\hline Type of Infertility & Number of patients & Percentage \\
\hline Primary & 45 & $56 \%$ \\
Secondary & 37 & $44 \%$ \\
\hline
\end{tabular}

Table-III

Female Causes of infertility $(n=82)$

\begin{tabular}{lcc}
\hline Cause of Infertility & No. of Patients & Percentage \\
\hline Tubal & 33 & $40.24 \%$ \\
Hypothyroid & 20 & $24.39 \%$ \\
Endometriosis & 12 & $14.46 \%$ \\
PCO & 11 & $13.41 \%$ \\
Hyper Prolactinemia & 4 & $4.88 \%$ \\
Uterus & 2 & $2.44 \%$ \\
\hline
\end{tabular}


Among women, different infertility factor included: Female factors responsible for infertility were in $82 \%$ cases (Table 3 ). The most common cause of female infertility was tubal factor and it was identified in 33 (40\%) women by laparoscopy or hysterosalpingography((HSG). Hypothyroidism was the second most common etiologic factors and identified in 20 (24.39\%) of infertile women by hormonal assay and clinical manifestation. Endometriosis was diagnosed in 12 (14.46\%) cases by laparoscopy as chocolate cyst in 7 cases and obliteration of pouch of doglus in 5 cases. Polycystic ovary syndrome was identified in 11 (13.41\%) women by ultrasonography, hormonal assay and clinical manifestation. Hyper prolactinemia was detected as the sole cause of infertility in 4 (4.88\%) cases. Uterine factor was recognized in 2 women. 1 woman with fibroid uterus and the other with Asherman's syndrome.

Table-IV

Semen Analysis $(n=100)$

\begin{tabular}{lcc}
\hline Parameters & $\begin{array}{c}\text { Number of } \\
\text { Patients }\end{array}$ & Percentage \\
\hline Sperm count (million/ml) & 0 & $0 \%$ \\
a. No sperm & 9 & $9 \%$ \\
b. $<20$ & 91 & $91 \%$ \\
c. $>20$ and above & & \\
Sperm morphology & 16 & $16 \%$ \\
a. $<30 \%$ normal & 84 & $84 \%$ \\
b. $>50 \%$ & 3 & $3 \%$ \\
a. non motile & 16 & $16 \%$ \\
b. $<30 \%$ motile & 81 & $81 \%$ \\
c. $>30 \%$ & &
\end{tabular}

Results of semen analysis showed that $72 \%$ of men had normal spermogram. No couple had azospermia, 28\% had sperm disturbance such as oligospermia, asthenospermia, oligoastheno -spermia and teratospermia.

\section{Discussion:}

In this study a relatively high frequency of primary infertility (56\%) was observed. While secondary infertility was determined in $44 \%$ of couples. These findings are comparable with that of Shayela and Banu's study which was done in the same institute in 1989 and 1993 respectively. ${ }^{6,7}$ The most comprehensive study of infertility - a WHO study of 5800 infertile couples seeking help at 33 medical centers in 22 developed and developing countries- found that most infertile couples around the world suffer from primary infertility ${ }^{(8)}$. Sub- Saharan Africa is an exception, where most couples $(52 \%)$ suffered from secondary infertility ${ }^{8}$. The mean age of female partners were $27.73 \pm 3.46$ years which are almost similar to some other reports $(9,10)$ from different countries.

In my study $66 \%$ couple reported with in 5 years of marriage. Among them only $20 \%$ reported with in 2 years of infertility. Mean duration of infertility at the time of presentation in the infertility unit $4.3 \pm 46$ years (range 2- 10 years) Study of infertility by Malekshah showed in his study that the duration of infertility was longer (5.7 \pm 4 years) (11). Infertile couples do not usually present in time to the infertility clinics due to inadequate general knowledge regarding infertility and about the presence of special centers in the country. Early attendance of infertile couple in their young age with lower duration of sub-fertility in infertility unit will be helpful for early assessment. They could be able to take best available method of treatment in their most fertile period.

The causes of infertility can be divided into four major categories: the female factor, the male factor, combined factors and unexplained infertility. Female and male factors were responsible in 57\% and 3\% cases respectively. In 25\% cases both male and female were responsible as combined factor infertility; remaining 15\% were unexplained infertility. Study of infertility by Malekshah showed in his study male factor consists $38.9 \%$ of infertility, female factor occurred in $34.7 \%$ of the infertile couples, in $14.6 \%$ of the couples both partners were involved and in $11.8 \%$ of couples no cause could be ascertained (11). Female factors responsible for sub fertility were in $82 \%$ cases (Table 3$) .33$ cases $(40 \%)$ were due to tubal factors. Endometriosis and poly cystic ovrian syndrome (PCO's) were 12 (14.63\%) and 11 (13.41\%) cases respectively. In a field study in central part of Iran (Yazd province), Aflatoonian etal (2009) reported female factor as the main cause of infertility (57.7\%) (12). In my study $33 \%$ cases were due to tubal factor whereas in Africa the incidence of tubal factors infertility is very high at $85 \%$ (13). Tubal occlusion is more prevalent in African countries because frequency of poorly treated STD is high (14-15). A survey of infertility in Royan Institute by kamali showed that most common cause of female infertility were ovarian factors (20.36\%) (10) and tubal factor infertility was $12.64 \%$, was mainly due to secondary Tuberculosis (TB). Though TB is highly prevalent in Bangladesh only 3\% infertile couple gave a past history of TB.

In this study, male factors were responsible in 28 cases (Table 4). Semen analysis report of 9 cases showed oligospermia i,e sperm count $<20 \mathrm{million} / \mathrm{ml}$. There was no case of azoospermia. In sperm motility in $3 \%$ cases it was totally non motile. In 16 cases motility was $<30 \%$. 
Kmali in his study showed that sperm disturbance (40.3\%) such as oligospermia, asthenospermia, oligoastheno-spermia and teratospermia were the most common etiologic factors responsible for male infertility ${ }^{10}$.

In my study history of infertility in first degree relatives was positive in $22 \%$ of women and $11 \%$ of men. Kamali at all identified history of infertility in first degree relatives was positive in $8.9 \%$ women and $10 \%$ men $^{(10)}$. Therefore a positive correlation between family histories of infertility in cases of infertile couple may be a possibility. Further study needed to prove association with it.

\section{Conclusion:}

Bangladesh is a developing country, where population burden is a big concern for the government. On the other hand reproduction is a basic human right; infertility leads to physical, psychological and social problem. Government needs to take care of infertility carefully, considering the above issues. It is recommended to take measures to improve the referral system, fertility health education and implementing infertility prevention programs. Moreover, merging all those small private clinics into private, public or states owned hospitals is suggested, in order to assure prompt, proper and adquate treatment.

\section{Conflict of Interest : None}

\section{References:}

1. Royal College of Obstetricians \& Ghynecologists. The initial investigation and management of the infertile couple. Guideline. London : RCOG: 2001.

2. Kds A, Nguyen T. Infertility in developing countries Reproductive health outlook 1997; 15;1-14.

3. Leke Rj, Bassol- Mayagoitia S. Bacha AM, Grigor KM. Regional and geographical variation in infertility : effects of environmental, cultural and socioeconomic factors. Environ Health Peerspect 1993; 101:73-80
4. Terava AN, Gissler M, Hemminiki E, Luoto R. Infertility and the use of infertility treatments in Finland; prevalence and socio-demographic determinants 1992-2004. Eur J Obsted Gynecol Reprod Biol 2008; 136:61-66

5. Wyshak G. Infertility in American college alumnae. International Jurnal of Gynecol Obstet 2001 ; 73: 237-242

6. Shayela S. A Clinical Study of 100 Cases of Infertility Attending $t$ he Infertility Clinic of IPGMR, Dhaka (Dissertation). Dhaka : Bangladesh College of Physicians and Surgeons, 1989

7. Banu. L.H Clinical Study on Aetiology and Diagnosis of Female Infertility (Dissertation). Dhaka : Bangladesh College of Physicians and Surgeons, 1993

8. Cates W, Farley TMM, Rowe PJ. Worldwide patterns of infertility. Is Africa|Different? Lancet 1985; 2: 596-598.

9. Esmeilzadeh S, Farsi M, Nazari T. The cause of infertility in the patients referring to Babol township fatemeh Zahra infertility center from May 1996 to May 1998. Jurnal of Mazandaran University of Medical Sciences 2002; 12:29-33.

10. Kamali M, Kashfi F, Baghestani AR, Kashani H, Tavajohi SH, Amirchaghmagh E. The epidemiologic survey on causes of infertility in patients refered to Royan institute. Medical Journal of Tabriz University of Medical Sciences 2006; 28:103-105

11. Mlekshah K.A Moghaddam EA- Infertility in Mazandaran province - North of Iran : an etiological study. Iranian Journal of Reproductive Medicine- 2011;. Vol- 9, No-1 PP21-24.

12. Aflatoonian A, Seyedhassani SM, Tabibnejad N. The edidemiological and etiological aspect to infertility in Yazd province of Iran, Iranian Journal of Reproductive Medicing 2009; 7:117-122.

13. Female Sub-fertility : In Obstetrics and Gynecology. Vol 1, 2nd ed. Calucutta: Orient Longman Ltd. 1999 -270-319.

14. Ikechebula Ji, Adinma J1, Orie EF lkegwuonu So. High prevalence of male infertility in southeastern Nigeria. J Obs Gyneco. 2003; 23(6): 657-659

15. Araoye MO. Epidemiology of infertility: social problems of the infertile couples. West Afr J Med. 2003; 22(2); 109-106. 